
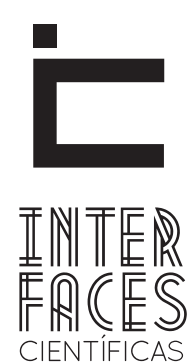

EDUCAÇÃO

ISSN IMPRESSO 2316-333X

ISSN ELETRÔNICO 2316-3828

\title{
APROPRIAÇÕES DO MÉTODO INTUITIVO PARA ENSINAR ARITMÉTICA EM ESCOLAS PRIMÁRIAS: ANALISANDO A LEGISLAÇÃO EDUCACIONAL BRASILEIRA - [1879-1930]
}

Marcus Aldenisson de Oliveira ${ }^{1}$

\section{RESUMO}

Este texto objetiva compreender de que forma o método intuitivo foi apropriado, por diferentes estados brasileiros para o ensino de Aritmética. Tal compreensão cria algumas possibilidades de conexão de elementos das histórias da educação matemática do curso primário entre as unidades estaduais. Para isso, a posição ocupada inicialmente é a de observador tentando acompanhar as similitudes e as particularidades de cada espaço. Como resultado, a pesquisa revela que com os reempregos atribuídos ao ensino de Aritmética, a partir da pedagogia intuitiva, contar e calcular deixaram de serem tópicos de conteúdos ancorados em regras fechadas e abstratas e transformaram-se em conhecimentos observados, palpável, vividos e adquiridos pelas experiências dos sentidos.

\section{PALAVRAS-CHAVE}

Apropriação. Aritmética do Curso Primário. Método Intuitivo. 


\section{ABSTRACT}

This text aims to understand how the intuitive method was appropriate for different Brazilian states for teaching Arithmetic. This understanding creates some possibilities of connecting elements of the stories of mathematics education from primary school between the state units. For this, the initially position is the observer - trying to follow the similarities and particularities of each space. As a result, the survey reveals that with the reuse allocated to the teaching of Arithmetic, from the

\section{RESUMEN}

Este trabajo, tiene como objetivo entender cómo el método intuitivo era apropiado para los diferentes estados de Brasil para la enseñanza de la Aritmética. Este entendimiento crea algunas posibilidades de conexión en elementos de la historia de la educación matemática de primaria entre las unidades estatales. Para ello, la posición ocupada originalmente es el observadortratando de mantenerse al día con las similitudes y particularidades de cada espacio. Como resultado, de la encuesta, revelase que, con reempleos asignados a intuitive pedagogy, count and calculate ceased to be anchored in content threads closed and abstract rules and turned into knowledge observed, palpable, lived and acquired the experiences of the senses.

\section{KEYWORDS}

Appropriation. Arithmetic of Primary School. Intuitive Method.

la enseñanza de Aritmética de la pedagogía intuitiva, se pasó a contar y calcular, dejado de estar anclado en temas de contenido cerrado y a reglas abstractas, y se convirtió en el conocimiento observado, palpable, adquiriéndose experiencias a través de los sentidos.

\section{PALABRAS CLAVE}

Apropiación. Aritmética de la escuela primaria. Método intuitivo. 


\section{INTRODUÇ̃̃̃o}

Tem-se para este texto uma análise dos documentos oficiais do ensino de diferentes estados brasileiros. Por certo, o desafio em vista é dialogar com as fontes do “outro". Tal diálogo se dará a partir dos vestígios deixados nos dispositivos normatizadores do ensino, cujo foco concentrar-se-á nos programas de ensino, nos materiais escolares e, em particular, na metodologia indicada para balizar a Aritmética do curso primário. 0 enfrentamento do desafio anunciado se coloca quando se tem por objetivo compreender de que forma o método intuitivo foi apropriado, no sentido ao termo dado pelo historiador Roger Chartier, por diferentes estados brasileiros para o ensino de Aritmética. Acredita-se que a análise possa revelar fragmentos da história dos saberes e práticas educacionais relativas a essa rubrica escolar no âmbito da circulação da pedagogia intuitiva.

A possibilidade desse cruzamento de fontes se caracteriza com a integração de pesquisadores de diversos cantos do país ao projeto maior "A Constituição dos Saberes Elementares Matemáticos: a aritmética, a geometria e o desenho no curso primário em perspectiva histórico-comparativa, 1890-1970”, desenvolvido com apoio do $\mathrm{CNPq}^{3}$.

Para este artigo interessa saber: Como diferentes estados brasileiros se apropriaram do método intuitivo para balizar o ensino de Aritmética em escolas primárias?

Para isso a pesquisa adota por marco temporal inicial o ano de 1879 por ter sido um ano inaugural de um período marcante entre as instabilidades dos sistemas de ensino, quando o Estado brasileiro foi inun-

3. Como parte integrante desse projeto guarda-chuva os resultados aqui apresentados é fruto da pesquisa de doutoramento "A circulação e apropriação do método intuitivo para o ensino de Aritmética: mudanças nos saberes elementares matemáticos dos anos iniciais (1880-1960)", desenvolvida no rol de estudos do Grupo de Pesquisa de História da Educação Matemática (GHEMAT/SP), e com defesa prevista para agosto de 2017. E mais, a pesquisa está sob a orientação do professor Dr. Wagner Rodrigues Valente e conta com o apoio financeiro da Fundação de Amparo à Pesquisa do Estado de São Paulo (Fapesp). dado pelos discursos de renovação e modernização da educação. Tais discursos se materializaram em decretos, reformas e programas de ensino, buscando institucionalizar a pedagogia intuitiva, inicialmente denominada de lições de coisas, como esperança de uma sociedade mais evoluída educacionalmente. Por outro lado, o limite final temporal se dá em 1930 porque, ao tudo indica, com o não-alcance da esperança passada os lideres intelectuais da educação brasileira daquele ano propuseram uma nova reformulação do ensino pelos métodos e preceitos pedagógicos, assegurando à sociedade sua transformação por um programa de nova educação para uma nova civilização ${ }^{4}$. Assim, o termo Escola Nova passou a representar novas práticas de reorganização da sociedade e de remodelação estrutural do sistema escolar (CARVALHO, 2003).

Neste ínterim, postula-se que alguns dispositivos orientadores de ensino tenderam a acompanhar aqueles movimentos pedagógicos. Com vista nisso, busca-se ainda, em perspectiva histórica, compreender se e como ocorreu a conformação do ensino de Aritmética primária a partir das orientações pedagógicas normatizadas pelos dirigentes da época, durante o movimento educacional intuitivo. Por outro lado, os indicadores almejados, também, sinalizam para o estudo da história das disciplinas escolares. Para a realização de tal estudo, indica Pessanha (2010), é possivel abordar a história das disciplinas escolares no interior da cultura escolar.

\section{HISTÓRIA DAS DISCIPLINAS ESCOLARES NO INTERIOR DA CULTURA ESCOLAR}

Algumas pesquisas que envolvem a história das disciplinas escolares têm como foco analisar a emer-

\footnotetext{
4. Expressões utilizadas por CARVALHO (2003, p. 96) para caracterizar os intentos do movimento educacional em se antagonizaram católicos e pioneiros.
} 
gência e a evolução das matérias que se tornaram escolares. No que tange às transformações sofridas ao longo tempo, a investigação da predominância de movimentos pedagógicos, da organização e estruturação dos conteúdos e dos métodos de ensino são categorias de análises que põem em revelo elementos da história das disciplinas. De acordo com o historiador André Chervel (1990, p. 185), coloca-se como objeto de estudo da história das disciplinas escolares três indicadores: a gênese (ao tentar entender como a escola operacionaliza os saberes); a função (buscando compreender a(s) finalidade(s) dos saberes difundidos pela escola, pondo em evidência o caráter criativo do sistema escolar); e por fim, a funcionalidade (que seria o elo entre a prática dos saberes pedagógicos e os resultados reais obtidos dessa operacionalização). Estas seriam, para Chervel, as categorias que balizam a constituição e o funcionamento as disciplinas escolares.

Olhando para as inovações e modernizações da educação que estão sempre atreladas aos movimentos pedagógicos, é possível dizer que a história das disciplinas escolares tem como elemento participante dessa história os métodos de ensino. Pois, os conteúdos e a rubrica de uma disciplina podem resistir às rupturas e mudanças educacionais. Coisa que não ocorre com a metodologia de ensino, que em muitos casos é o ponto de partida para emergir os discursos de transformações da educação. Sendo assim, o estudo da história das disciplinas deve, contudo, considerar os elementos que se unem para difundir aquilo que é trazido por tal matéria, a saber: a linguagem utilizada para transmissão dos saberes e os materiais didáticos designados para auxiliar na sua aplicação. Portanto, torna-se necessário ficar atento ao corpus de dispositivos que materializa a disciplina escolar e que são responsáveis por criar formas de transmitir o conhecimento consolidado na instituição de ensino pela rubrica de matéria escolar.

As formas de transmissão do conhecimento de uma disciplina são criações espontâneas e originais do sistema escolar. $\mathrm{O}$ que faz da instituição de ensino um lugar detentor da criatividade. Por certo disso, Chervel (1990, p. 187) enxerga que a escola "forma não somente os indivíduos, mas também uma cultura que vem por sua vez penetrar, moldar, modificar a cultura da sociedade global". Cultura que, na visão de Chartier, pode ser vista como aquilo que "articula as produções simbólicas e as experiências estéticas subtraídas às urgências do cotidiano, com as linguagens, os rituais e as condutas, graças aos quais uma comunidade vive e reflete sua relação ao mundo, aos outros e a si mesma" (CHARTIER, 2010, p. 16).

A comunidade escolar é, por certo, um espaço social que possibilita que seus agentes vivam e reflitam as suas relações com o mundo, com os outros e cada um consigo mesmo. Nela, na escola, uma cultura emerge e, por conseguinte, manifestasse no produzido e no vivido das urgências do cotidiano escolar, afetando, assim, os significados do meio escolar que dão vida e funcionalidade ao seu dia a dia. Contudo, pode-se dizer que a função pedagógica da escola está atrelada aos símbolos, práticas, linguagens, rituais, condutas e urgências da vida cotidiana construída pelos seus agentes principais - os alunos e os professores. Em outras palavras, o espaço escolar também é portador de cultura. Ao que se pode denominar de cultura escolar ${ }^{5}$.

Como produtos que compõem, também, a cultura escolar, os programas de ensino, por sua vez, são dispositivos que institucionalizam o que e como se deve ensinar. Neles, nos programas, compartilham-se os modos de pensar as disciplinas e suas finalidades. Eles ainda oferecerem pistas que permitem o pesquisador obter certa "aproximação" do cotidiano escolar por meio de alguns elementos. Não se quer dizer, contudo, que esta "aproximação" configure o vivido no cotidiano escolar, pois os

\footnotetext{
5. Para Julia (2001, p. 10) cultura escolar pode ser entendida como "[...] um conjunto de normas que definem conhecimentos a ensinar e condutas a inculcar e um conjunto de práticas que permitem a transmissão desses conhecimentos e a incorporação desses comportamentos".
} 
programas de ensino em particular silenciam vários acontecimentos que personificam o dia a dia escolar, tais como: as práticas desenvolvidas nas urgências do cotidiano escolar; os gestos físicos e orais dos professores e dos alunos.

Ainda que não contenha tudo sobre a vivência escolar, algumas fontes da legislação educacional podem ser vistas como elementos que configuram uma cultura escolar por se caracterizarem como documentos que possibilitam o historiador observar rudimentos do processo histórico, cultural e pedagógico vivenciados por estes durante o período de sua institucionalização e da sua circulação.

Os escritos que foram apresentados até aqui talvez tenham carregado alguns condicionamentos de justificação da escolha de estudar a história das disciplinas escolares no interior da cultura escolar. Pois, como diz o próprio Chervel (1990), a escola também é formadora de uma cultura, a qual se personifica nas práticas, nas linguagens, nos rituais e nas condutas, que interfere diretamente na(s) história(s) das disciplinas escolares. Embora, seja sabido que a história das disciplinas relacione-se com as exigências legais, haverá sempre nessa história marcas culturais de um espaço das possibilidades - da escola (GATTI JÚNIOR, 2010). Verifica-se que é possível apreender elementos da cultura produzida pela escola expressos na história das disciplinas (PESSANHA, 2010).

Desvelar a escolarização da Aritmética no curso primário brasileiro em diferentes tempos e espaços é, contudo, uma tentativa de evidenciar as transformações de saberes que se tornaram escolares não obedece a uma linearidade lógica, resultando, contudo, de injunções que assumem características específicas em cada tempo e em cada espaço (SOUZA JÚNIOR E GALVÃO, 2005). Para isso, tomam-se como prisma as circulações e as apropriações do método intuitivo para o ensino de Aritmética, valendo-se de tais fontes: os Relatórios de Diretores de Instrução Pública; Reforma do ensino; Decretos; Regulamento e Programas de ensino das escolas primárias e dos Grupos Escolares; Fala da Assembleia Legislativa Provincial/ Estadual; Mensagens de Presidente do Estado apresentada à Assembleia Legislativa; Relatórios de Movimentação anual da Escolar.

\section{CIRCULAÇÃO DO MÉTODO INTUITIVO: INTEPRETACÕES, REEMPREGOS E USOS PARA 0 ENSINO DE ARITMÉTICA}

O ano de 1879 e a década vindoura foram períodos marcados pelos discursos e debates políticos em torno da educação. A situação do ensino no país foi, e continua sendo até os dias de hoje, indicada como uma necessidade de organização da sociedade em conformidade à remodelação do sistema escolar. Para a educação, buscou-se uma organização tanto na estrutura física dos espaços escolares como na escolha dos conteúdos a serem ensinados e da metodologia de ensino a ser utilizada. Este período, de modo geral, pode ser caracterizado pelos constantes deslocamentos dos sistemas de ensino. É nesse contexto que o Estado brasileiro faz da educação um grande espetáculo, promovendo estratégias como Conferências, Congressos e Exposições Pedagógicas e constantes projetos de reforma do ensino (BASTOS, 2005, p. 116).

Outra ação estratégica utilizada por lideres de grupos participantes do poder para uma transformação da sociedade foi a lógica da comparação da realidade educacional do Brasil em relação aos países da Europa e ao sistema de ensino dos Estados Unidos. Ou seja, o país se mostrava ter conhecimentos contemporâneos sobre os debates educacionais de outros espaços. Tais conhecimentos foram apropriados e abriram os caminhos para a modernização e inovação da educação no Brasil, como: a instalação de prédios escolares; a padronização do sistema escolar; a institucionalização de um programa a ser seguido; o estabelecimento de 
uma metodologia de ensino; a profissionalização do professorado. Para Valdemarin e outros autores (2013, p. 240), nesse contexto “[...] o método intuitivo foi elemento pedagógico imprescindível para estabelecer diferenciações entre o futuro desejado e a realidade a ser modificada [...]".

Na urgência de se modernizarem na instrução as unidades estaduais do Brasil, também, se apropriaram de tal modelo de instrução que tinha suas bases de sustentação na metodologia renovadora da época - o método intuitivo. Os diálogos com os escritos de Chartier $(1990,1995)$ apontam que, para o presente estudo, apropriação passa a ser entendida por meio dos caracteres particulares de apreender e reempregar ideias pedagógicas, bem como os sentidos que se configuraram a partir dessas interpretações.

Contudo, a noção de apropriação é concebida no sentido de identificar diferentes modos com os quais as representações, acerca do método intuitivo, foram sendo construídas pelos atores que normatizaram, estruturam e/ou deliberam a quem, o que e como se deveria ensinar na escolar. O(s) modo(s) que autoridades educacionais (ou chefes do poder) prescreveram o ensino de Aritmética, tendo o método intuitivo como metodologia, demonstra as relações de leituras e de adaptações dos princípios dessa pedagogia - o que provavelmente resultou na remodelação de práticas e saberes elementares dessa disciplina escolar no curso primário brasileiro.

O desvelar das apropriações das concepções intuitivas se dá a partir de análises comparativas entre as normatizações presentes na legislação educacional de diferentes estados do Brasil. Essas comparações intentam, dentre outros pontos, criar algumas possibilidades de conexão de elementos das histórias da educação matemática en- tre as unidades estaduais. Para isso, a posição ocupada inicialmente é a de observador - tentando acompanhar as similitudes e as particularidades de cada espaço.

Para esta investigação, não se almeja apontar as peculiaridades sociais, políticas e econômicas que personificam e revelam as realidades dos estados, e que sem dúvidas refletem nas apropriações dos objetos e/ ou ideias em circulação. Busca-se, contudo, perceber as variações de interpretações e reempregos que o mesmo modelo pedagógico apresentou para o ensino de Aritmética. Procura-se, ainda, acompanhar o movimento da circulação de ideias pedagógicas, considerando que as distintas relações de leituras, de reempregos e usos do método intuitivo provocaram deslocamentos tanto nos saberes e práticas quanto na constituição da Aritmética do curso primário em tempos da vaga intuitiva.

Sendo assim, para a análise pretendida tomaram-se alguns documentos oficias dos estados que integram a plataforma de banco de dados do Repositório de Conteúdo Digital. Foram eles, os estados: Alagoas; Amazonas; Bahia; Espírito Santo; Goiás; Mato Grosso; Minas Gerais Paraná; Rio de Janeiro (Distrito Federal, para o período); Rio Grande do Norte; Rio Grande do Sul; Roraima; Santa Catarina; São Paulo e Sergipe.

O Quadro abaixo expressa, de modo global, como em cada período alguns estados pensaram o ensino de Aritmética para a escola primária, tanto metodologicamente como na incorporação de materiais escolares. A ausência de alguns estados é justificada pela falta de documentos do curso primário compreendidos no marco temporal delimitado ou não sendo possível abordar nem o método de ensino nem materiais escolares utilizados. 
Quadro 1 - Prescrições legais ao método de ensino e materiais escolares indicados ao curso primário brasileiro para o ensino de Aritmética (1879 a 1930)

\begin{tabular}{|c|c|c|c|}
\hline \multicolumn{4}{|l|}{ De 1879 a 1899} \\
\hline $\begin{array}{l}\text { Província/ } \\
\text { Estado }\end{array}$ & Ano & Método de ensino & Materiais escolares para o ensino \\
\hline Rio de Janeiro/DF & 1879 & $\begin{array}{l}\text { Método intuitivo ou lições de } \\
\text { coisas. }\end{array}$ & Não evidenciados. \\
\hline Bahia & $1881.1 ; 1887$ & O ensino intuitivo. & $\begin{array}{l}\text { Numerador mecânico; algarismos móveis; taboa } \\
\text { preta para exercícios de Aritmética; compêndios } \\
\text { métricos de Pape-Carpantier; arithmetro de Petry; } \\
\text { grandes jogos instrutivos pelos sistemas de Pesta- } \\
\text { lozzi e Froebel. }\end{array}$ \\
\hline \multicolumn{4}{|l|}{ De 1890 a 1899} \\
\hline Estado & Ano & Método de ensino & Materiais escolares para o ensino \\
\hline Rio de Janeiro/DF & 1890 & Método intuitivo. & Objetos concretos; contador mecânico; ábacos. \\
\hline Sergipe & 1890 & Método intuitivo. & $\begin{array}{l}\text { Aritmometro de Arens; contador mecânico; coleções } \\
\text { de padrões do sistema de pesos e medidas. }\end{array}$ \\
\hline Bahia & 1893 & Ensino intuitivo. & Não evidenciados. \\
\hline Mato Grosso & 1893; 1896; 1897 & $\begin{array}{l}\text { Os princípios do método intui- } \\
\text { tivo. }\end{array}$ & Não evidenciados. \\
\hline São Paulo & 1894 & Processos intuitivos. & Auxílio de objetos concretos. \\
\hline \multicolumn{4}{|l|}{ De 1900 a 1909} \\
\hline Estado & Ano & Método de ensino & Materiais escolares para o ensino \\
\hline Sergipe & 1901 & Método intuitivo & Não evidenciados. \\
\hline São Paulo & 1905 & Não evidenciado. & $\begin{array}{l}\text { Por meio concretos com o auxílio de tabuinhas ou de } \\
\text { tornos de sapateiro. }\end{array}$ \\
\hline Rio de Janeiro/DF & 1907 & Método intuitivo. & Objetos concretos; contador mecânico; ábacos. \\
\hline Santa Catarina & $1907 ; 1908 ; 1909$ & $\begin{array}{l}\text { Processo mental usados nas } \\
\text { escolas de São Paulo. }\end{array}$ & Quadros de Parker. \\
\hline Espírito Santo & 1908 & 0 método intuitivo. & Não evidenciados. \\
\hline
\end{tabular}




\begin{tabular}{|c|c|c|c|}
\hline \multicolumn{4}{|l|}{ De 1910 a 1919} \\
\hline Estado & Ano & Método de ensino & Materiais escolares para o ensino \\
\hline Mato Grosso & $\begin{array}{l}1910 \\
1916\end{array}$ & $\begin{array}{l}\text { O ensino intuitivo, concreto e } \\
\text { prático. }\end{array}$ & Cartas de Parker; grãos de milho; tornos; varetas. \\
\hline Sergipe & $1912 ; 1914 ; 1917$ & $\begin{array}{l}\text { Método objetivo prático e in- } \\
\text { tuitivo. }\end{array}$ & $\begin{array}{l}\text { Objetos concretos para o ensino intuitivo; mapas para o en- } \\
\text { sino de Aritmética e do sistema métrico; cartas de Parker; }\end{array}$ \\
\hline Santa Catarina & 1914 & Método intuitivo e prático. & Objetos concretos; quadros de Parker; \\
\hline Bahia & 1915 & O ensino intuitivo e prático. & Não evidenciados. \\
\hline Paraná & 1916 & Método intuitivo. & $\begin{array}{l}\text { Contador; mapas de Parker; mapas linguagem Arit- } \\
\text { mética; coleções quadros de Barreto. }\end{array}$ \\
\hline São Paulo & 1918 & Tudo indica os processos intuitivos. & Objetos concretos. \\
\hline \multicolumn{4}{|l|}{ De 1920 a 1930} \\
\hline Estado & Ano & Método de ensino & Materiais escolares para o ensino \\
\hline Santa Catarina & 1920 & O ensino intuitivo e prático. & Coleção de objetos concretos; quadro de Parker. \\
\hline Paraná & 1920; 1921; 1928 & O ensino intuitivo e prático. & $\begin{array}{l}\text { Objetos concretos, servindo-se de tornos, tabuinhas, } \\
\text { palitos e etc.; contador mecânico; cartas ou mapas de } \\
\text { Parker; mapas decimal. }\end{array}$ \\
\hline São Paulo & $1921 ; 1925$ & O ensino intuitivo e prático. & $\begin{array}{l}\text { Objetos concretos para o manuseio, como: tornos, ta- } \\
\text { buinhas, cubos, lápis, favas, pedrinhas e etc; mapas } \\
\text { de Parker; contados mecânico. }\end{array}$ \\
\hline Rio de Janeiro/DF & 1923 & Método intuitivo e prático. & Objetos concretos. \\
\hline Sergipe & 1923 & $\begin{array}{l}0 \text { ensino intuitivo e prático } \\
\text { úteis à vida. }\end{array}$ & Não evidenciados. \\
\hline Goiás & $1925 ; 1930$ & Ensino intuitivo. & $\begin{array}{l}\text { Objetos concretos para manusear: tornos, palitos, } \\
\text { tabuinhas, cabos, lápis, pedras, etc.; outros objetos } \\
\text { separados por cores e tamanha; Mapas ou taboa de } \\
\text { Parker; Contador mecânico. }\end{array}$ \\
\hline Rio Grande do Norte & 1925 & Método intuitivo. & Objetos concretos; contador mecânico; mapas de Parker; \\
\hline Minas Gerais & 1927 & Direcionamentos intuitivos ${ }^{1}$. & Coleção de pesos e medidas. \\
\hline Mato Grosso & 1927 & $\begin{array}{l}\text { Seguiu os princípios do méto- } \\
\text { do intuitivo. }\end{array}$ & $\begin{array}{l}\text { Mapas de Parker; contador mecânico; mapas de Pe- } \\
\text { sos e Medidas. }\end{array}$ \\
\hline Santa Catarina & 1928 & Método intuitivo. & Objetos concretos; mapa do sistema métrico. \\
\hline
\end{tabular}

Fonte: quadro elaborado a partir de dados encontrados em parte das fontes legislativas do Banco de dados do Repositório de Conteúdo Digital - UFSC. 
Observando as informações apresentadas, evidencia-se, no discurso oficial, a predominância do método intuitivo para o ensino de Aritmética, de forma quase unânime. Para os materiais escolares indicados e/ ou utilizados, podem-se dizer as mesmas palavras unanimidade nas escolhas. Esta leitura inicial revela a primeira semelhança comum: a ação relativamente inseparável entre a adoção dos processos intuitivos e a incorporação dos materiais escolares para o ensino de Aritmética no curso primário brasileiro. Pelo analisado, tudo leva a acreditar que a apropriação dessa pedagogia para o sistema de instrução primária provocou algumas mudanças e rupturas nas práticas escolares aritméticas, em particular. Por assim conjecturar, coloca-se a seguinte pergunta: como essas mudanças e rupturas se configuraram nos documentos analisados? A resposta não se encontra nas fontes de forma previsível, pronta e nem está posta nos documentos de modo linear. Para isso, é preciso desvelar alguns pormenores das fontes analisadas.

Não se pretende fazer uma hierarquização numérica desses pormenores. Entretanto, pode-se apontar de início que o modelo de instrução paulista serviu de elo entre os diferentes estados e a pedagogia intuitiva. Pois, com o advento do sistema governamental republicano o estado paulista depositou na educação esperanças de um futuro melhor.

O principal diferencial proclamando pelos republicanos paulistas é visto pelos seguintes pontos: a reestruturação da escola, dos processos de ensino e a formação do professor. Nesse sentido, segundo Valdemarin e outros autores (2013), o ponto inicial foi conferido a Caetano de Campos que liderou a reforma da Escola Normal de São Paulo, fazendo dela o modelo dos projetos educacionais que adotavam a pedagogia intuitiva como marco da inovação. Essa escola tinha em anexo a Escola Modelo, a qual preparava, também, os futuros professores a partir da nova concepção psicológica da infância, afirmada pelos processos intuitivos.
Assim como a país utilizou-se da lógica comparativa para legitimar uma identidade nacional para a educação, tendo outros países como espelho, as unidades estaduais, também, enxergaram em São Paulo um modelo de instrução a ser seguido. Com o propósito de fazer parte da modernização educacional, diferentes estados brasileiros passaram a contratar professores normalistas formados em São Paulo para reformar seus respectivos sistemas de instrução pública. Por exemplo, o relatório de Governo de 1911 de Santa Catarina, registra na página 65 que para a reforma da instrução públicas catarinense foi contratado em 1910 o professor Orestes de Oliveira Guimarães e a sua esposa Dona Cacilda Rodrigues Guimarães, ambos de São Paulo.

O envio de professores normalistas para a capital paulista caracteriza-se, também, como outra ação que possibilitou o relativo "ingresso" dos estados na modernização do ensino primário. Isto é, os diálogos dos estados brasileiros com os processos intuitivos muitas vezes ocorreram a partir do canal de círculo concêntrico, assim denominado por Darnton (2010), se São Paulo era o centro produtor e difusor dos ideais de renovação educacional, então a contratação de pessoas integrantes daquele sistema de ensino paulista e o envio de professores normalistas para terem contato prático com os princípios do método intuitivo podem ser vistos como canais do sistema de comunicação que irradiaram tais ideais.

Algumas mudanças e rupturas, possivelmente se configuraram a partir da apropriação de plurais objetos escolares, para dá suporte didático ao ensino de Aritmética. Os processos intuitivos atribuíam importâncias à observação das coisas e manipulação dos objetos concretos. 0 aluno para aprender número, as quatro operações, as frações e o sistema decimal, por exemplo, não estaria limitado apenas a um conhecimento abstrato, dedutivo.

Tudo indica que as Cartas de Parker eram vistas como processos práticos da aprendizagem intuitiva 
de Aritmética6. Sua cópia e/ou leitura, como era indicado pelos programas de ensino, tinha como finalidade levar o aluno a romper com o ensino de cor, pretendendo, contudo, que a mente da criança se desenvolvesse, associando os ensinamentos de Aritmética às coisas. No que diz respeito a isso, Valente (2013) aponta que as coisas passariam a dar lições sobre os números.

Talvez seja possível supor que a presença das Cartas de Parker no curso primário brasileiro configure uma das mudanças mais claras nas práticas escolares para o ensino de Aritmética intuitiva: ensinar a contar e a calcular simultaneamente a grande número de alunos, em um espaço curto tempo e com o abandono da lição de cor pelas lições com e pelas coisas. Além disso, esse instrumento pedagógico confere à aprendizagem de adição, subtração, multiplicação e divisão outros rumos - situações de lições orais: atividades em que o professor mira um conjunto de objetos e pergunta aos alunos, os quais, olhando para as estampas ali presentes tendem a adicionar, diminuir, multiplicar e/ou dividir mentalmente e, em seguida, responder.

Outra tentativa de ruptura e mudança se caracteriza ao passo em que aprender Aritmética tende a ser uma atividade de exercício reflexivo executado pelo cálculo mental. Esse tipo de exercício oral seguiria uma metodização progressiva que acompanhava 0 ritmo de desenvolvimento da criança. Diferente do cálculo escrito, precedido por regras fechadas e prontas, o cálculo mental é um ensino vivo, que desperta o interesse na classe e que coloca os cérebros em atividade - uma excelente ginástica intelectual ${ }^{7}$.

Pelo analisado, o cálculo mental era mais uma forma de otimização do tempo de aprendizagem, pois não havia a necessidade de gastar o tempo com a for-

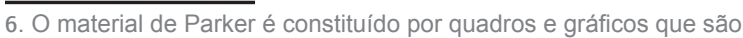
acompanhados de explicações e instruções ao professor. Ele representa a forma de tratar o ensino de Aritmética de modo ativo, na moderna pedagogia do ensino primário (VALENTE, 2013).

7. Cf. o Programa de Ensino do Curso Primário para os Grupos Escolares e Escolas Isoladas, 1925, SP, p. 30. mação e decoração da tabuada ${ }^{8}$. Uma das atividades da prática de cálculo mental que aparece em grande parte dos documentos analisados são as situações de pagamentos de contas quando envolvem casos para os trocos.

Para familiarizar a criança com a ideia de número, alguns programas de ensino, também, prescrevem que o professor não fique apenas utilizando a sequência natural dos números $(1,2,3,4, \ldots)$, mas que os escrevam por grupos e, por conseguinte, fora da ordem para que o aluno possa identificar cada número por um golpe de vista (expressão utilizada pelos programas). Essa racionalidade lógica tem como intento que a criança desenvolvesse o bom manejo com os números. Tudo indica que não ser mais admissível pelos princípios do método intuitivo que o sujeito decore a sequência numérica.

Entretanto, o aprendizado de algarismo (número) passa por um momento de quebra de sequenciamento dos números: ordem arbitraria, em grupos distintos de números. Tudo continua a indicar que esse postulado se configura como mais um marco na ruptura metodológica para o ensino de número, na proposta intuitiva: o abandono da mecanização de decorar a sequência numérica, recomendando que a criança aprenda cada número mentalmente de forma significativa. Isto é, um aprendizado, ligando os números aos objetos e, despertando a percepção quantitativa das coisas, e não o seu ordenamento. As distribuições não ordenadas e não linear das estampas que compõem as Cartas de Parker são exemplos reais desta ruptura ${ }^{9}$.

Evidencia-se, assim, que o ensino intuitivo e prático de Aritmética tem por finalidade abandonar as regras preestabelecidas e dedutivas. Contudo, precisasse fornecer os meios necessários de adquirir conhecimento para que a criança com o seu ato espon-

\footnotetext{
8. Cf. o Programa de Ensino para as Escolas Primárias Diurnas - Distrito Federal, 1923, RJ, p. 11.

9. Cf. Valente $(2008$, p. 6$)$.
} 
tâneo e (cri)ativo educar-se a si mesma: questionando aquilo alcançado pelos sentidos; reconstruindo seus conhecimentos por meio das percepções e das reflexões; seguindo as suas inclinações intuitivamente, nos momentos empíricos. 0 uso desta pedagogia para ensinar Aritmética permite e requer que a criança identifique situações reais de conhecimento aritmético na vida cotidiana.

Olhando os documentos de modo global, a disciplina Aritmética é concebida como matéria de ensino incumbida de transmitir os primeiros rudimentos de números, correlacionar estes números entre as operações de soma, subtração, multiplicação e divisão, trabalhar com as frações, achar uma quantidade desconhecida pela regra de três, operacionalizar as dimensões e os pesos e outros aprendizados elementares com os números.

Com o olhar mais específico para o que se almeja nesta investigação, talvez seja possível conjecturar que o método intuitivo confere ao ensino de Aritmética primária o realce de uma matéria prática: aprender essa ciência escolar tenderá associar as intuições com as práticas, de modo que se sobressaia os exercícios mentais de percepção, reflexão, comparação e julgamento. A criança precisa estar fazendo alguma atividade, pois enquanto ela age, aprende. Manusear e observar as coisas/objetos passa a serem ações intuitivas e práticas que conduz o indivíduo a contar, a medir, a pesar e a comparar. Estas são algumas constatações evidenciadas pelo exame dos documentos.

\section{CONSIDERAÇÕES FINAIS...}

Pelo analisado é possível dizer que a pedagogia intuitiva que circulou entre 1879 e 1930, por escolas primárias brasileiras, deslocou a ideia de que o conhecimento de Aritmética era adquirido de forma unilateral - via professor. Tal deslocamento mexeu com algumas bases cognitivas da criança: a percepção, comparação e reflexão permaneceram atreladas à observação e manuseio dos objetos e das coisas da natureza. Isso não só afetou o cotidiano escolar do aluno, mas o do professor também.

0 método intuitivo, ancorado nas lições coisas, prescrito nos documentos oficias indica que para 0 bom uso de seus princípios faz-se necessário colocar a criança diante de situações em que os sentidos estejam em ação. Para o ensino de Aritmética a maioria dos programas aqui analisados evidencia que o professor deve munir-se de objetos concretos, para que a criança experimentasse e sentisse suas impressões sensíveis. Com esses reempregos atribuídos ao ensino de Aritmética, contar e calcular deixaram de serem tópicos de conteúdos ancorados em regras fechadas e abstratas e transformaram-se em conhecimentos observados, palpável, vividos e adquiridos pelas experiências dos sentidos.

Por meio do investigado é possível conjecturar que a chegada dessa pedagogia promove uma ruptura e mudança na prática escolar do ensino de Aritmética, fazendo com que o aluno deixe de ser um "depósito de ideias alheias" e passe a ser um sujeito dotado de sensibilidade - sua ação ativa sobre a vida e o mundo são condições de construção do conhecimento aritmético. Nesse sentido, vale dizer que se o método é intuitivo, o ensino é ativo.

A circulação e a presença dos materiais escolares indicados para o ensino de Aritmética configuraram um momento da cultura escolar primária. Tais materiais revelam o possível suporte didático que eles conferiram à pedagogia intuitiva: novas formas de se ensinar os saberes aritméticos com o apelo à observação, à manipulação, à experimentação, à comparação e à prática. As apropriações destes dispositivos por diferentes estados do país asseguraram tanto a essa metodologia como às práticas escolares de Aritmética outras interpretações, reempregos e modos de usos. Quanto às práticas nada é possível afirmar como elas de fato ocorreram, pois em nenhum momento dos documentos examinados foi possível evidenciar o modo 
como tais materiais foram operacionalizados. 0 que fica constatado é apenas a institucionalização do uso daqueles materiais pedagógicos para fins aritméticos.

Os dados aqui apresentados possibilitam inferir que a pedagogia intuitiva promoveu mudanças nas práticas escolares para ensinar Aritmética no curso primário brasileiro de 1879 a 1930 (mas como essas práticas se configuraram? Eis a questão que demanda outras investigações).

\section{REFERÊNCIAS}

BASTOS, Maria Helena Camara. A educação como espetáculo. In: STEPHANOU, Maria e BASTOS, Maria Helena Camara (Orgs.) História e memória da educação no Brasil. V. II: Século XIX. Petrópolis, RJ: Vozes, 2005, p. 116-131.

CARVALHO, Marta Maria Chagas de. A escola e a República e outros ensaios. Bragança Paulista: EDUSF, 2003. (Estudos CDAPH. Série historiografia).

CHARTIER, Roger. Escutar os mortos com os olhos. Revista Estudos Avançados/USP, v.69, n.24, 2010.

CHARTIER, Roger. A História Cultural: entre práticas e representações. Tradução Maria Manuela Galhardo. Rio de Janeiro: Bertrand Brasil, 1990.

CHERVEL, André. História das disciplinas escolares: reflexões sobre um campo de pesquisa. Revista Teoria \& Educação, n.2, 1990, p. 177-231.

DARNTON, Robert. 0 beijo de Lamourette: mídia, cultura e revolução. São Paulo: Companhia das Letras, 2010.

GATTI JÚNIOR, Décio. Aspectos teórico-metodológicos e da historiografia brasileira na temática da história das disciplinas escolares (1990-2008). Revista Tempos e Espaços em Educação, São Cristóvão/SE, v.4, n.4, 2010, p. 9-30.
JULIA, Dominique. A cultura escolar como objeto histórico. In: Revista Brasileira de História da Educação. Campinas/SP: Autores Associados, n.1, jan/dez, 2001, p. 9-43.

PESSANHA, Eurize Caldas. História de disciplinas escolares em uma "escola exemplar" em Mato Grosso do Sul: possibilidade de uma história da cultura escolar (1939-2002). Revista Tempos e Espaços em Educação, São Cristóvão/SE, v.4, n.4, 2010, p. 31-41.

SOUZA JÚNIOR, Marcílio e GALVÃO, Ana Maria de Oliveira. História das disciplinas escolares e história de educação: algumas reflexões. Revista Educação e Pesquisa, São Paulo, v.31, n.3, set./dez. 2005, p. 391-408.

VALDEMARIN, Vera Teresa; TEIVE, Gladys Mary Ghizoni e HANDAM, Juliana Cesário. Modernidade Metodológica e Pedagógica: apropriações do método de ensino intuitivo nas reformas da instrução pública de Minas Gerais, Santa Catarina e São Paulo (1906-1920): ideias e práticas em movimento. In: SOUZA, R. F. de; SILVA, V. L. G. da e SÁ, E. F. de (Orgs). Por uma teoria e uma história da escola primária no Brasil: investigações comparadas sobre a escola graduada (1870-1930). Cuiabá: EdUFMT, 2013, p. 239-272.

VALENTE, Wagner Rodrigues. Do ensino ativo para a escola ativa: Lourenço filho e o material de Parker para a Aritmética do curso primário. In: 36 ${ }^{a}$ Reunião Nacional da ANPEd (2013). Anais eletrônico disponível em <http://36reuniao.anped.org.br/pdfs_trabalhos_aprovados/gt02_trabalhos_pdfs/gt02_2746_ texto.pdf>. Acesso em: 25 out. 2013.

VALENTE, Wagner Rodrigues. O ensino intuitivo e as cartas de Parker. In: V Congresso Brasileiro de História da Educação (2008). Anais eletrônico. Disponível em: < http://www.sbhe.org.br/novo/congressos/ cbhe5/pdf/528.pdf>. Acesso em: 7 fev. 2014. 
Recebido em: 6 de Março de 2014 Avaliado em: 10 de Março de 2014 Aceito em: 10 de Março de 2014
1. Doutorando no Programa de Pós-Graduação em Educação e Saúde na Infância e na Adolescência - Universidade Federal de São Paulo/UNIFESP Campus Guarulhos. E-mail: marcus_aldenisson@ hotmail.com 